\title{
Cytotoxic, cytostatic and anti-estrogenic effect of Thymoquinone on estrogen receptor-positive breast cancer MCF7 cell line
}

\author{
Marjaneh Motaghed \\ Oncology Science Cluster, Advanced Medical and Dental Institute, University Sains Malaysia, Penang, Malaysia
}

Email address:

marjaneh_motaghed@yahoo.com

To cite this article:

Marjaneh Motaghed. Cytotoxic, Cytostatic and Anti-Estrogenic Effect of Thymoquinone on Estrogen Receptor-Positive Breast Cancer MCF7 Cell Line. American Journal of Life Sciences. Special Issue: The Most Effective Medicinal Plants in Cancer Treatment.

Vol. 3, No. 2-2, 2015, pp. 7-14. doi: 10.11648/j.ajls.s.2015030202.12

\begin{abstract}
About $80 \%$ of breast cancers are estrogen-receptor positive. The research carried out herein focused on the effect of Thymoquinone which is an active compound of Nigella sativa seed on estrogen-receptor positive breast cancer MCF7 cell line. The percentage of apoptotic cells was found using Annexin V-FITC apoptosis detection kit. CycleTEST PLUS DNA Reagent was used to distinguish distribution of treated cells between different cell cycle phases. DNA microarray identified the regulated genes, level of expressed genes, gene ontology and pathway networks. Significant arrest of treated cells at $\mathrm{G}_{1}$ phase suggested cytostatic effect of Thymoquinone $100 \mu \mathrm{M}$ after 24 hours at $p$-value $<0.05$ which was similar to anti-estrogenic compounds such as Tamoxifen. Cytotoxic effect of Thymoquinone $100 \mu \mathrm{M}$ was found through highly significant accumulation of cells at sub- $\mathrm{G}_{1}$ phase after 72 hours at $p$-value $<0.0001$. CYP1A1, CYPIB1, NQO1 and UGTIA8 genes were down regulated after 24 hours treatment with Thymoquinone $50 \mu \mathrm{M}$ concentration which suggested reduction of catechol estrogens and rising in metoxy forms of estradiol and estrone. Reduction of ER would be predictable due to the down-regulation of CYPIBI and UGTIA8 genes which reduced affinity of trans-tamoxifen-o-glucuronide to ER. The study proposed the benefits of using Thymoquinone to accelerate Tamoxifen effects in treating breast cancer and reducing its side effects.
\end{abstract}

Keywords: Thymoquinone, Tamoxifen, Anti-Estrogenic Effect, Cell Cycle, Apoptosis Assay, cDNA Microarray

\section{Introduction}

Cancer has been known as the second leading cause of mortality in developing countries and the leading cause of death even in developed countries [1]. Proliferation of mammary epithelial cells is dependent to the level of estrogens. The lifetime exposure to estrogen is a main factor to promote cancer in hormone-dependent organs such as breast [2]. Based on previous studies, anti-estrogen compounds still remain the choice of treatment for hormone dependent breast cancers. It is revealed that the growth inhibition effects of anti-estrogen compounds are through the arrest at $\mathrm{G}_{0} / \mathrm{G}_{1}$ phase of the cell cycle [3]. The mechanism of cell cycle arrest at $G_{0} / G_{1}$ phase due to anti-estrogen agents is correlated with the reduction of cyclin D1 gene expression and inactivation of cyclin D1-Cdk4 complexes and reduction of $\mathrm{pRb}$ phosphorylation $[4,5,6]$.

One of the most important anti-estrogen compounds is Tamoxifen which is known as a first-line drug to treat estrogen-receptor positive (ER+) breast tumors [7]. Tamoxifen has ability to block the $\mathrm{G}_{1}$ phase of the cell cycle and as a result slows breast cancer cell proliferation [8]. Tamoxifen prevents cancerous cells from dividing but not causes death. Previous studies have described that Tamoxifen is an inhibitory growth agent which blocks breast cancer cells at $\mathrm{G}_{0} / \mathrm{G}_{1}$ region of the cell cycle [9].

The efficiency of many plants has been reported in the treatment of cancer from ancient until present [10]. About $25 \%$ of prescribed drugs in the world are originated from plants [11]. More than 3000 species of plants are reported to have anti-cancer properties [12]. In this study, it was tried to understand the anti-estrogenic effect of Thymoquinone derived from Nigella sativa seed on the MCF7 breast cancer cell line. 


\section{Materials and Methods}

\subsection{Apoptosis Assay}

The MCF7 cell line was purchased from American Type Culture Collection (ATCC, USA). The cells were cultured in RPMI 1640 (Invitrogen, Gibco, US) containing L-glutamine supplemented with $10 \%$ heat-inactivated fetal bovine serum (Invitrogen, Gibco, US) and 1unit penicillin/streptomycin (Hyclon). Annexin V-FITC apoptosis detection kit (BD Bioscience, USA) was used to stain apoptotic cells. Adherent MCF7 cells with concentration of $1.0 \times 10^{6}$ cells $/ \mathrm{ml}$ were treated with various concentrations $(0 \mu \mathrm{M}, 25 \mu \mathrm{M}, 50 \mu \mathrm{M}$, and $100 \mu \mathrm{M}$ ) of Thymoquinone and incubated for 12 and 24 hours at $37^{\circ} \mathrm{C}$ in humidify atmosphere $\mathrm{CO} 2$ incubator. The staining procedure was performed according to the manufacturer's protocol and analyzed by flow cytometry (BD FACSCanto II) using FACSDiva program.

\subsection{Cell Cycle Analysis}

CycleTEST PLUS DNA Reagent Kit (BD Bioscience, USA) was used to discriminate distribution of cells between different cell cycle phases. MCF7 cells at a density of $1.0 \times$ $10^{6}$ cells $/ \mathrm{ml}$ were treated with Thymoquinone at concentration $25 \mu \mathrm{M}, 50 \mu \mathrm{M}$, and $100 \mu \mathrm{M}$ for 12 hours, 24 hours and 72 hours. The number of cells was calculated with flow cytometry (BD FACSCanto II) using ModFit software.

\subsection{Gene Expression Analysis}

Total RNA was extracted from MCF7 cells using RNeasyPlus Mini kit protocol (QIAGEN, USA). RNA quantity and quality were done using Agilent Technologies' protocol. Gene expression analysis was performed using Agilent two-color microarray. Reference design was applied using the Universal Human Reference RNA (Agilent Technologies, USA) which acted as an internal control. Four biological replicates of Thymoquinone-treated MCF7 cells were compared with four biological replicates of un-treated MCF7 cells on the same array slide platform. The results were scanned with a fluorescent scanner and qualified with Feature Extraction software. Gene expression level, identification of genes, gene ontology and pathway networks were evaluated using GeneSpring software.

\section{Results}
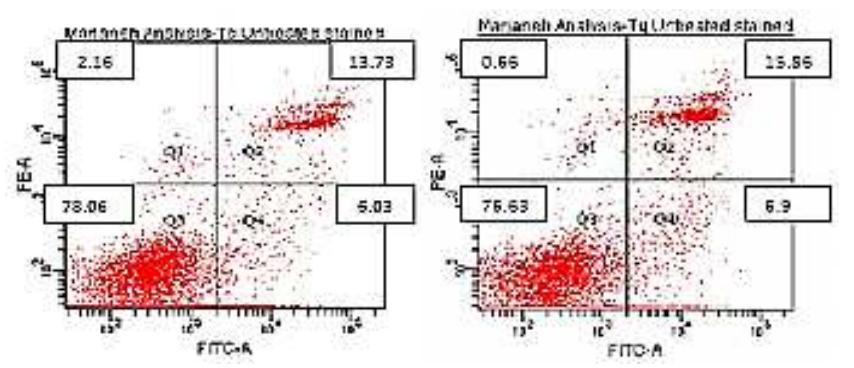

(1)
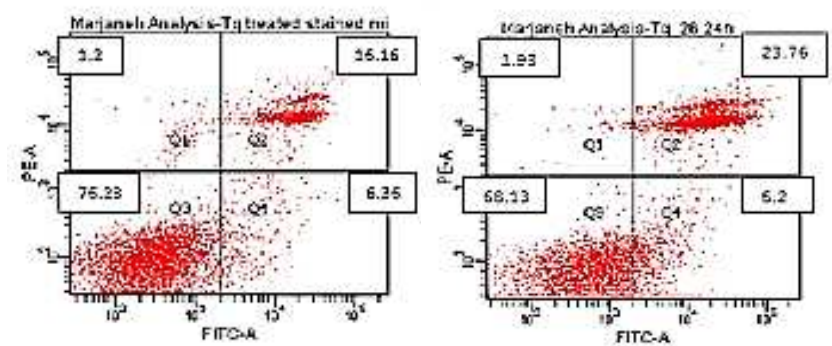

(2)
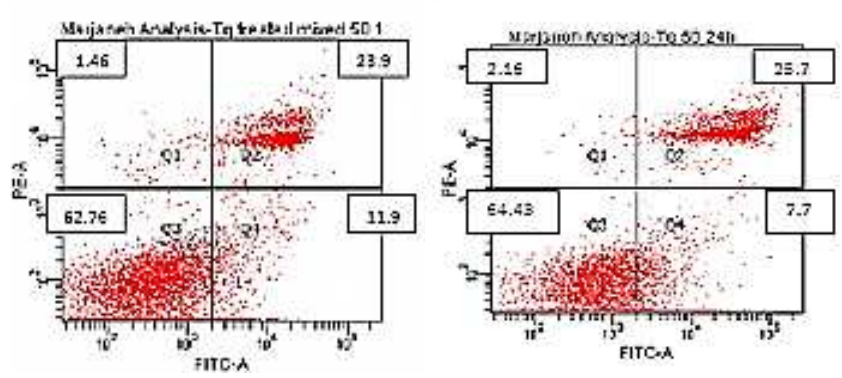

(3)

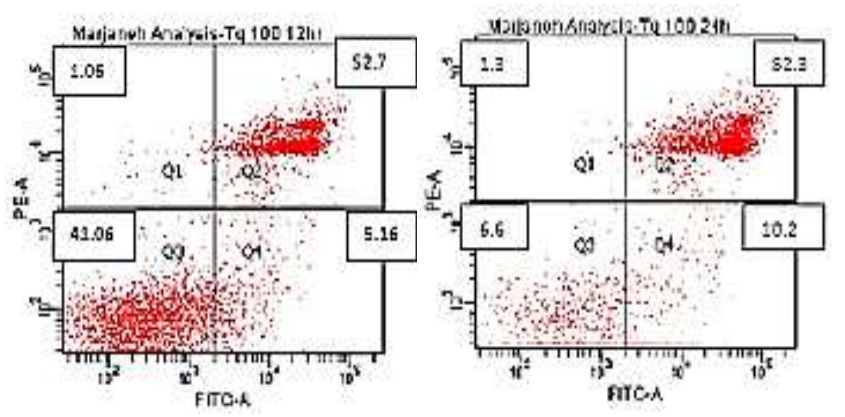

(4)

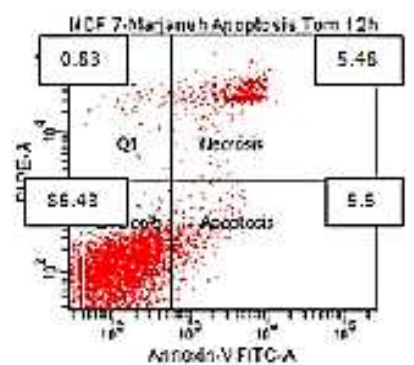

(a)

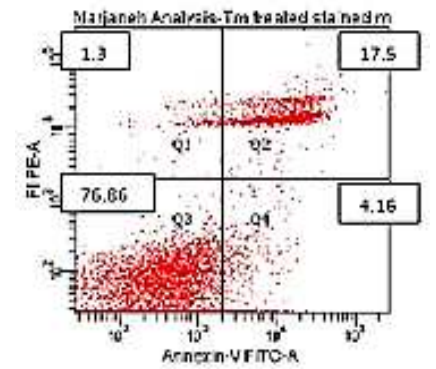

(5)

(b)
Figure 1. Flow cytometric evaluations of MCF-7 cells after 12 hours (a) and 24 hours $(b)$ exposure to various concentrations of Thymoquinone (1) $0 \mu M$, (2) $25 \mu M$, (3) $50 \mu M$, (4) $100 \mu M$ and (5) Tamoxifen $5 \mu M$. Annexin $V$ apoptosis assay revealed the decrease in the population of viable cells while a growing shift was appeared in the percentage of apoptotic and necrotic cells. The results obtained from biological triplicate experiments.

The results revealed that the number of viable cells after 12 hours treatment with Thymoquinone decreased when the concentrations of treatment was increased from $25 \mu \mathrm{M}$ to 100 
$\mu \mathrm{M}$, however it was not statistically significant. The ANOVA test results showed a significant decrease in the percentage of viable cells ( $p$-value $<0.0002)$ and a significant increase in the late apoptosis ( $p$-value $<0.0001)$ after treatment with $100 \mu \mathrm{M}$ concentrations for 24 hours which indicated the highly toxic effect of Thymoquinone $100 \mu \mathrm{M}$ concentration "Fig 1".

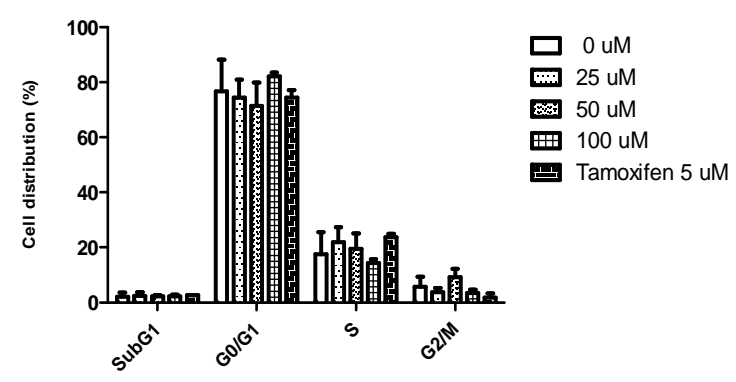

(a)

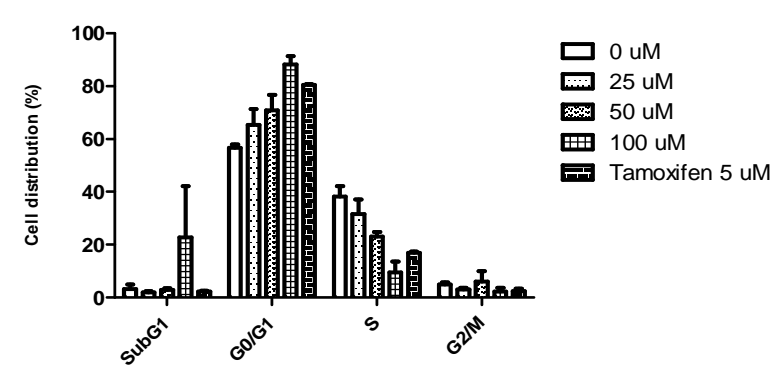

(b)

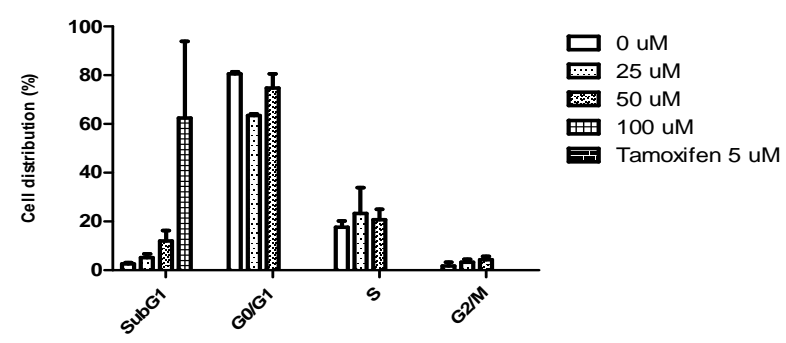

(c)

Figure 2. Comparison between Thymoquinone-treated and Tamoxifen-treated MCF7 cells in different cell cycle phases at (a) 12 hours, (b) 24 hours and (c) 72 hours. The mean \pm SD of cell distribution was calculated using three independent experiments.

Repeated-measure two-way ANOVA showed that there were significant differences between time, concentration and various cell cycle phases at $p$-value $<0.001$. The cell cycle analysis revealed that Thymoquinone $100 \mu \mathrm{M}$ concentration is a highly toxic dosage for breast cancer MCF7 cell after 24 hours because of the significant increase $(31.61 \%)$ of the cell arrest at $\mathrm{G}_{1}$ phase and significant decrease $(28.87 \%)$ of the cell synthesis at $\mathrm{S}$ phase. The presence of the $60 \%$ of apoptotic cells in the sub- $G_{1}$ phase after 72 hours of treatment with Thymoquinone $100 \mu \mathrm{M}$ concentration indicated time and dose dependent mode of Thymoquinone. On the other hand, Tamoxifen $5 \mu \mathrm{M}$ concentration showed the inhibition of cell cycle at $\mathrm{S}$ phase significantly which was $21 \%$ and the arrest of cells at $\mathrm{G}_{1}$ phase was $24 \%$ after 24 hours. A large number of cells after 72 hours treatment with Tamoxifen $5 \mu \mathrm{M}$ concentration moved to necrosis stage.

Comparison between Thymoquinone and Tamoxifen revealed that after 12 hours treatment with Thymoquinone 100 $\mu \mathrm{M}$ concentration, it caused the highest percentage of cell arrest at $G_{1}$ phase compared to Tamoxifen and the other its concentrations. The less number of cells were in $\mathrm{S}$ phase for Thymoquinone $100 \mu \mathrm{M}$ concentration. While the arrest of cells at sub- $G_{1}$ and $G_{2} / M$ phases with Thymoquinone treatment were almost similar to Tamoxifen, the results are provided in Table 1.

Increasing the treatment duration to 24 hours caused a greater accumulation of cells at $G_{1}$ phase for Thymoquinone $100 \mu \mathrm{M}$ concentration. Besides, the lowest number of cells was in $\mathrm{S}$ phase for Thymoquinone $100 \mu \mathrm{M}$ concentration as presented in Table 2.

After 72 hours, the effect of inhibition was found with Thymoquinone $100 \mu \mathrm{M}$ concentration which was through accumulation of cells at sub- $\mathrm{G}_{1}$ phase and reduction of cells to zero at the other phases of cell cycle. Prolonged exposure of cells to the treatments till 72 hours revealed the less number of cells at all cell cycle phases following treatment with Tamoxifen. The findings confirmed the strong effect of Tamoxifen on MCF-7 cells after 72 hours treatment as shown in Table 3.

Presence of a prominent sub- $\mathrm{G}_{1}$ peak which is a distinct region below $G_{1}$ phase represents apoptotic bodies [13]. In the current study, there was a distinguished increase in the percentage of cells at sub- $\mathrm{G}_{1}$ region with Thymoquinone 100 $\mu \mathrm{M}$ concentration after 24 hours and highly significant changes after 72 hours which indicated on the cytotoxic effect of Thymoquinone.

It is worth to mention that the effect of Thymoquinone on estrogen receptor-positive MCF7 breast cancer cell line was cytostatic similar to the Tamoxifen function which was found through accumulation of cells at $\mathrm{G}_{1}$ phase especially after 24 hours with $100 \mu \mathrm{M}$ concentration. Existence of other evidence also confirmed this finding which emphasized that exposure to Tamoxifen $(5 \mu \mathrm{M}$ to $12.5 \mu \mathrm{M})$ resulted in a dose-dependent reduction in the number of breast cancer $\mathrm{MCF} 7$ cells progressing through $\mathrm{G}_{1}$ and entering $S$ phase [14].

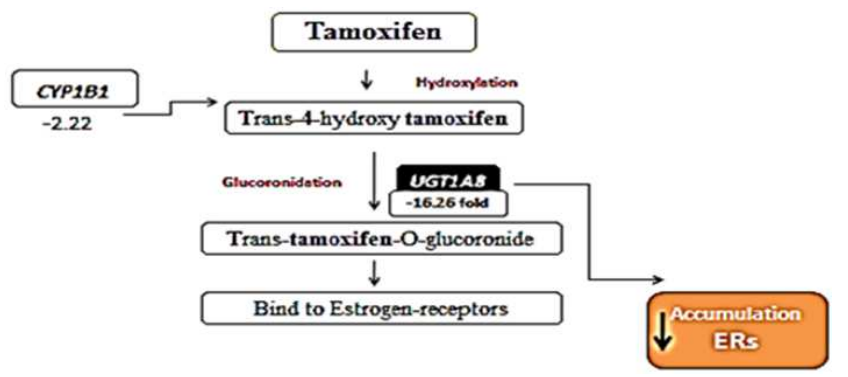

Figure 3. Gene expression regulation in Tamoxifen pathway following Thymoquinone (50 $\mu \mathrm{M} / 24$ hours) treatment. The down-regulation of CYP1B1 and UGT1A8 decrease the conversion of trans-4-hydroxy-Tamoxifen to trans-tamoxifen-4-o-glucuronide, thereby; the formation of trans-Tamoxifen-4-o-glucuronide would increase and produce less number of ER. 
Microarray results revealed the down-regulation of some of genes involved in estrogen pathway including UGT1A8 (-16.26 -fold change), CYP1A1 (-2.22 -fold change), CYP1B1 (-2.23 -fold change) and NQO1 (-2.07 -fold change). Down-regulation of UGT1A8 (-16.26 -fold change), CYP1B1 (-2.23 -fold change) was found in Tamoxifen pathway after treatment of cells with Thymoquinone "Fig 3".

\section{Discussion}

Thymoquinone (2-methyl-5-isopropyl-1,4-benzoquinone, TQ) is known as a bioactive component of volatile oil of Nigela sativa seed [15]. Previous studies showed that Thymoquinone can be an effective agent in treating hormone sensitive prostate cancers [16]. Furthermore, it is known as anti-cancer in breast and ovarian adenocarcinoma [17], colorectal cancer [18], human pancreatic adenocarcinoma [19, 20], lung carcinoma [21], uterine sarcoma [19], neoplastic keratinocytes [22], human osteosarcoma [23], fibrosarcoma [21], anti-oxidant and anti-inflammatory [24]. In this study, anti-estrogenic effect of Thymoquionone on MCF-7 breast cancer cell was proposed.

Three major estrogens in humans produced in ovaries of pre-menopausal women are 17 $\beta$-Estradiol (E2), Estrone (E1), Estriol (E3) [25]. Estradiol is known as the main and most active endogenous estrogen in pre-menopausal women. It is present in the form of estrone in post-menopausal women [26] and estriol in pregnant women [29]. The elevation of circulating estrogen level is reported to cause an increased risk of breast cancer [30].

The metabolism of estrogen is catalyzed by phase I xenobiotic enzymes involving cytochrome $\mathrm{P} 450$ pathway which included $C Y P 1 A 1$ and $C Y P 1 B 1$ genes [29,30,31]. $C Y P 1 A 1$ and $C Y P 1 B 1$ genes are known as phase I enzymes involved in the oxidative metabolism of endogenous estrogens, 17-beta estradiol and estrone to catechol estrogens [30,32]. Furthermore, $C Y P 1 B 1$ gene is one of the anti-cancer therapeutic targets for a variety of cancers [33]. The CYP1A1 is a protein of cytochrome P450, family 1, subfamily A, polypeptide 1 [34]. It is expressed in extra hepatic tissues such as mammary gland, prostate, ovary, uterus, colon, testis, adrenal, thymus and lung [35]. On the other hand, CYP1B1 belongs to the cytochrome P450, family 1, subfamily B, polypeptide 1 and is expressed in many normal human tissues such as mammary gland [32] and prostate [36]. Estradiol is hydroxylated to produce 2-hydroxyestradiol (2-OHE2) and 4-hydroxyestradiol (4-OHE2) [32] and this conversion is regulated by $C Y P 1 A 1$ and $C Y P 1 B 1$ genes, respectively [37,38]. The over-expression of $C Y P 1 B 1$ is reported in up to $73 \%$ of human breast cancer and other hormone-dependent tumors $[32,39,40,41]$. The presence of CYP1B1 protein is more detectable in mammary tumors than normal breast tissues [32]. In fact, the elevated level of hydroxylated estradiol in estrogen-responsive tissues might play an essential role in tumor genesis [39]. The carcinogenic effect of estrogen was associated with 4-OHE2 $[42,43]$. The 4-OHE2 is known as a tumor promoter $[37,38]$. There are many reports which showed the relationship of conversion of E2 to 4-OHE2 in mammary carcinogenesis with CYPIB1 [42]. The two hydroxylated metabolites of $\mathrm{E} 2$ are oxidized and converted to E2-2, 3-Q and E2-3, 4-Q, respectively [32]. Quinine metabolites of estrogen can form DNA adducts and act in response to DNA to become carcinogenic metabolites of breast cancer $[30,43,44]$.

The findings of microarray analysis in this study indicated the down-regulation of $C Y P 1 B 1$ following the treatment of MCF-7 cells with Thymoquinone. The low expression of $C Y P 1 B 1$ gene could suppress the conversion of E2 to 4-OHE2 in estrogen pathway. It could potentially lead to a reduction in carcinogenic metabolites of E2. Thus, it suggested that the formation of carcinogenic metabolites of estrogen (E2-2, 3-Q and E2-3, 4-Q) could be controlled by Thymoquinone.

Naturally, the methylation process causes 2, 4-OHE2 to be metabolized and forms 2-, 4-MeOE2 [25]. The process of methylation can be regulated under effect of UGT1A8 gene [45]. The 4-MeOE2 is non-cancerous metabolite of estrogen and also 2-MeOE2 which has an apoptotic activity. The 2-MeOE2 is the major form of methylated catechol estrogens that has anti-cancerous and anti-angiogenic effect $[37,46]$. Nowadays, Panzem which is the trade name of 2-MeOE2 is using to suppress tumor development and block the formation of new blood vessels that supply tumors [47]. In the current study, the down-regulation of UGT1A8 gene suggested the accumulation of 2-MeOE2 in Thymoquinone-treated cells and might inhibit the conversion of 2-MeOE2 to glucuronide form. This might ultimately direct the cells towards apoptosis and prevent cell proliferation and angiogenesis.

Tamoxifen (TAM, 1-[4-(2-dimethylaminoethoxy) phenyl] -1, 2-diphenylbut-1 (Z) -ene) is a non-steroidal and anti-estrogen which serves as an option in breast cancer treatment [47]. Tamoxifen is reported to increase the level of 4-OHE2 [37]. Elevation in the expression level of CYP1B1 was also reported due to Tamoxifen treatment however, the expression level of $C Y P 1 A 1$ gene decreases due to Tamoxifen effect [37,38]. Previous study reported up-regulation of CYP1B1 due to the Tamoxifen metabolites which induce uterine cancer [32].

In the current study, the conversion of trans-4-hydroxytamoxifen to trans-Tamoxifen-4-o-glucuronide would decrease due to the down-regulation of $C Y P 1 B 1$ and UGT1A8 genes. Trans-Tamoxifen-4-o-glucuronide is an active metabolite of Tamoxifen due to its high affinity to estrogen receptors [47]. Thereby, less formation of trans-Tamoxifen-4o-glucuronide would cause less accumulation of ER. Moreover, the EGF-EGFR is an important pathway which leads to the phosphorylation of ER. The over-expression of both ER and EGFR promote breast cancer growth [48]. In the current study, the microarray findings showed down-regulation of GPCR, EGF and EGFR signalling pathways following treatment with Thymoquinone which suggested the down-regulation of ER. Previously, it was postulated that Thymoquinone potentially stimulate ER to transmit signal via GPCR and EGFR [49]. Hence, down-regulation of GPCR and EGF-EGFR signalling 
pathways in the current study would cause reduction of ER which is highly expressed in luminal A sub-type MCF-7 breast cancer cell line. There are many studies introduced Tamoxifen as an alternative for the treatment of a wide-range of tumors, particularly in breast cancer. Regardless of Tamoxifen benefits, it also presents unwanted side effects [50]. The Tamoxifen metabolites up regulate the level of $C Y P 1 B 1$ gene which promotes uterine cancers [32] while Thymoquinone caused down-regulation of $C Y P 1 B 1$.

Co-administration of Thymoquinone and Tamoxifen on breast cancer cells (MCF-7 and MDA-MB-231) reported a significant reduction of the level of XIAP phosphorylation which could cause inhibition of Akt pathway. Besides, the inhibition of MAPK/ERK pathway after combination therapy is reported which lead to the suppression of tumor genesis [50]. A previous in vivo study showed that the co-administration of Thymoquinone $20 \mathrm{mg} / \mathrm{kg}$ orally and Tamoxifen $5 \mathrm{mg} / \mathrm{kg}$ orally in nude mouse xenograft model promote an increase in the expression level of Bax, p27, AIF, cytochrome $\mathrm{c}$ and a decrease in $B c l 2$ and $B c l-x L$ expression level [50].

The presence of another form of estrogen which is estrone (E1) is reported in postmenopausal women [26]. It is metabolized to 2-, 4-OHE1. The 4-OHE1 is known as one of the most potent carcinogenic estrogen metabolites [37].
Whereby, 2-, 4-MeOE1 is produced after methylation. The methoxy forms of estrone are known as good estrogens to human and show anti-cancer and anti-angiogenic potency at increased level [37].

The down-regulation of UGT1A8 would lead to the accumulation of metoxy form of estrone. The current study also showed the down-regulation of another gene which is involved in the production of the methylated form of E2 and $\mathrm{E} 1$. The $\mathrm{NAD}(\mathrm{P}) \mathrm{H}$ : quinine oxido-reductase 1 is an enzyme that is encoded by the NQO1 gene and known as a detoxification enzyme [51]. It acts in phase II of detoxification to catalyze quinines to non-toxic hydro quinines [52]. It is implicated in the protection against carcinogenesis reactions [53]. This study showed down-regulation of this gene by 2.07 fold after a treatment with Thymoquinone $50 \mu \mathrm{M}$ concentration. Its expression has influence on the conversion of 2-OHE1 to E1-2, 3-Q, thus leading to DNA damage. The down-regulation of NQO1 gene would maintain the conversion of 2-OHE1 to 2-MeOE1. The 2-MeOE1 is reported to act as an anti-proliferative metabolite and anti-angiogenic agent [37,54]. Similarly, a previous study showed that Tamoxifen causes an increase in the expression level of NQO1 gene [37].

Table 1. The mean $\pm S D$ of cell distribution after 12 hours treatment with Thymoquinone $(25 \mu M, 50 \mu M, 100 \mu M)$ and Tamoxifen $5 \mu M$ concentration

\begin{tabular}{llll}
\hline & Sub-G1 & G1 & S \\
\hline Untreated $(0 \mu \mathrm{M})[$ Negative control] & $2.16 \pm 2.05$ & $76.72 \pm 16.4$ & $17.48 \pm 11.4$ \\
Thymoquinone $(25 \mu \mathrm{M})$ & $2.39 \pm 2.24$ & $74.39 \pm 11.4$ & $21.87 \pm 9.57$ \\
Thymoquinone $(50 \mu \mathrm{M})$ & $2.19 \pm 0.80$ & $71.35 \pm 14.7$ & $19.42 \pm 9.70$ \\
Thymoquinone $(100 \mu \mathrm{M})$ & $2.28 \pm 0.87$ & $82.16 \pm 2.30$ & $14.39 \pm 2.20$ \\
$\begin{array}{l}p \text {-value between } \\
\text { different concentration of Thymoquinone }\end{array}$ & 0.998 & & \\
Tamoxifen $(5 \mu \mathrm{M})[$ Positive control] & $2.65 \pm 0.08$ & 0.726 & 0.753 \\
\hline
\end{tabular}

Table 2. The mean $\pm S D$ of cell distribution after 24 hours treatment with Thymoquinone $(25 \mu M, 50 \mu M, 100 \mu M)$ and Tamoxifen $5 \mu M$ concentration

\begin{tabular}{|c|c|c|c|c|}
\hline & Sub-G1 & G1 & $\mathbf{S}$ & G2/M \\
\hline Untreated $(0 \mu \mathrm{M})$ [Negative control] & $03.10 \pm 2.50$ & $56.66 \pm 1.70$ & $38.33 \pm 5.30$ & $04.99 \pm 1.05$ \\
\hline Thymoquinone $(25 \mu \mathrm{M})$ & $01.88 \pm 0.94$ & $65.31 \pm 10.3$ & $31.65 \pm 9.60$ & $04.55 \pm 1.06$ \\
\hline Thymoquinone $(50 \mu \mathrm{M})$ & $02.86 \pm 1.10$ & $70.98 \pm 9.90$ & $23.04 \pm 3.10$ & $05.98 \pm 6.80$ \\
\hline $\begin{array}{l}\text { Thymoquinone }(100 \mu \mathrm{M}) \\
p \text {-value between }\end{array}$ & $22.76 \pm 33.5$ & $88.27 \pm 5.30 *$ & $09.46 \pm 7.08 * *$ & $03.40 \pm 2.50$ \\
\hline different concentration of Thymoquinone & 0.479 & $\begin{array}{l}0.016 \\
*\end{array}$ & $\begin{array}{l}0.0077 \\
* *\end{array}$ & 0.668 \\
\hline
\end{tabular}

* Significant at $p$-value $<0.05$

$* *$ Significant at $p$-value $<0.01$

Table 3. The mean $\pm S D$ of cell distribution after 72 hours treatment with Thymoquinone $(25 \mu M, 50 \mu M, 100 \mu M)$ and Tamoxifen $5 \mu M$ concentration

\begin{tabular}{|c|c|c|c|c|}
\hline & Sub-G1 & G1 & $\mathbf{S}$ & G2/M \\
\hline Untreated $(0 \mu \mathrm{M})$ [Negative control] & $02.69 \pm 0.90$ & $80.57 \pm 1.70$ & $17.74 \pm 4.35$ & $01.68 \pm 2.80$ \\
\hline Thymoquinone $(25 \mu \mathrm{M})$ & $05.20 \pm 2.70$ & $63.45 \pm 1.20$ & $23.27 \pm 18.3$ & $03.28 \pm 2.20$ \\
\hline Thymoquinone $(50 \mu \mathrm{M})$ & $11.94 \pm 7.60$ & $74.86 \pm 9.80$ & $20.81 \pm 7.30$ & $04.32 \pm 2.60$ \\
\hline $\begin{array}{l}\text { Thymoquinone }(100 \mu \mathrm{M}) \\
p \text {-value between }\end{array}$ & $62.57 \pm 54.2^{* * *}$ & $0 * * *$ & $0 * *$ & 0 \\
\hline different concentration of Thymoquinone & $\begin{array}{l}<0.0001 \\
* * * *\end{array}$ & $\begin{array}{l}<0.0001 \\
* * * *\end{array}$ & $\begin{array}{l}<0.0001 \\
* * * *\end{array}$ & 0.277 \\
\hline
\end{tabular}

* Significant at $p$-value $<0.05 ; * * *$ Significant at $p$-value $<0.001$

$* *$ Significant at $p$-value $<0.01$; **** Significant at $p$-value $<0.0001$ 
In conclusion, the findings of current study suggested reverse effect of Thymoquinone on ERs; hence its administration along with Tamoxifen might be a new suggests reducing the side effect of Tamoxifen which causes uterine cancer.

\section{Acknowledgements}

This study was funded by Universiti Sains Malaysia Advanced Medical and Dental Postgraduate Fund. The author would like to express thanks to all staff of different clusters of Advanced Medical and Dental Institute for their cooperation.

\section{References}

[1] National Cancer Institute, Global Cancer Research Programs., 2013. [Online]. Available at: <http://www.cancer.gov/research and funding/priorities/global-research-activities. Accessed on 1th Nov 2013.

[2] Krishnan, A.V., Swami. S., Feldman, D., 2012. The potential therapeutic benefits of vitamin $\mathrm{D}$ in the treatment of estrogen receptor positive breast cancer. Steroids 77, 1107-1112.

[3] Steigerová, J., Oklest'ková., Levková, M., Rárová, L., kolárr, Z., Strnad, M., 2010. Brassinosteroids cause cell cycle arrest and apoptosis of human breast cancer cells. Journal of Chemico-Biological Interactions 188, 487-496.

[4] Song, L., Dong, W., Gao, M., Li, J., Hu, M., Guo, N, Huang, C., 2010. A novel role of IKK $\alpha$ in the mediation of UVB-induced G0/G1 cell cycle arrest response by suppressing Cyclin D1 expression. Biochimica et Biophysica Acta (BBA)-Molecular Cell Research 1803, 323-332.

[5] Watts, C.K.V., Brady, A., Sarcevic, B., Defazio, A., Musgrove, E.A., Sutherland, R.L., 1995 Antiestrogen inhibition of cell cycle progression in breast cancer cells is associated with inhibition of cyclin-dependent kinase activity and decreased retinoblastoma protein phosphorylation. Molecular Endocrinology 9, 1804-1813.

[6] Musgrove, E.A., Hamilton, J.A., Lee, C.S., Sweeney, K.J., Watts, C.K., Sutherland, R.L., 1993. Growth factor, steroid, and steroid antagonist regulation of cyclin gene expression associated with changes in T-47D human breast cancer cell cycle progression. Molecular. Cell. Biology 13, 3577-3587.

[7] Yang, J.J., Park, S.K., CHO, L.Y., Han, W., Park, B., Kim, H., Lee, K.S., Haahn, S.K., Cho, S.I., Ahn, S.H., Noh, D.Y., korean breast cancer society., 2010. Cost-Effectiveness Analysis of 5 Years of Postoperative Adjuvant Tamoxifen Therapy for Korean Women with Breast Cancer. Clinical Therapeutics 32, 1122-1138.

[8] Clemons, M., Danson, S., Howell, A., 2002. Tamoxifen ("Nolvadex"): a review. Cancer Treatment Review 28, 165-180.

[9] Sutherland, R.L., Hall, R.E., Taylor, I.W., 1983. Cell Proliferation Kinetics of MCF-7 Human Mammary Carcinoma Cells in Culture and Effects of Tamoxifen on Exponentially Growing and Plateau-Phase Cells. Cancer Research 43, 3998-4006.
[10] Gurib-fakim, A., 2006. Medicinal plants: Traditions of yesterday and drugs of tomorrow. Molecular Aspects of Medicine 27, 1-93.

[11] Rates, S.M.K., 2001. Plants as source of drugs. Toxicon 39, 603-613.

[12] Graham, J.G., Quinn, M.L., Fabricant., D.S., Farnsworth, N.R., 2000. Plants used against cancer - an extension of the work of Jonathan Hartwell. Journal Ethnopharmacology 73:347-377.

[13] Da Silva, C.P., De Oliveira, C.R., DA Conceicao, P., De Lima, M., 1996. Apoptosis as a Mechanism of Cell Death Induced by Different Chemotherapeutic. Bio-chemical Pharmacology 51, 1331-1340.

[14] Taylor, I.W., Hodson, P.J., Gren, M.D., Sutherland, R.L., 1983. Efects of Tamoxifen on Cell Cycle Progresion of Synchronous MCF-7 Human Mammary Carcinoma Cells. Cancer Research 43, 4007-4010.

[15] Kara, M.I., Ereiyas, K., Altan, A.B., Ozkut, M., AY, S., Inan, S., 2012. Thymoquinone accelerates new bone formation in the rapid maxillary expansion procedure archives of oral biology 57, 357-363.

[16] Gullett, N.P., Ruhul Amin, A.R., Bayraktar, S., Pezzuto, J.M., Shin, D.M., Khuri, F.R., Aggarwal, B.B., Surh, Y.J., Kucuk, O., 2010. Cancer Prevention with Natural Compounds. Seminars in Oncology 37, 258-281.

[17] Shoieb, A.M., Elgayyar, M., Dudrick, P.S., Bell, J.L., Tithof, P.k., 2003. In vitro inhibition of growth and induction of apoptosis in cancer cell lines by Thymoquinone. International Journal of Oncology 22, 107-113.

[18] Gali-Muhtasib, H., Diab-Assaf, M., Boltze, C., Al-Hmaira, J., Hartig, R., Roessner, A., Schneider-Stock, R., 2004a. Thymoquinone extracted from black seed triggers apoptotic cell death in human colorectal cancer cells via a p53-dependent mechanism. International Journal Oncology 25, 857-66.

[19] Worthen, D.R., Ghosheh, O.A,, Crooks, P.A., 1998. The in vitro anti-tumor activity of some crude and purified components of blackseed, Nigella sativa L. Anticancer Research 18, 1527-1532.

[20] Torres, M.P., Ponnusamy, M.P., Chakraborty, S., Smith, L.M., Das, S., Arafat, H.A., Batra, S.K., 2010. Effects of Thymoquinone in the Expression of Mucin 4 in Pancreatic Cancer Cells: Implications for the Development of Novel Cancer Therapies. Molecular Cancer Therapy 9, 1419-1431.

[21] Kaseb, A., Chinnakannu, K., Chen, D., Sivanandam, A., Tejwani, S., Menon, M., Dou, Q., Reddy, G., 2007. Androgen receptor and E2F-1 targeted Thymoquinone therapy for hormone-refractory prostate cancer. Cancer Research 67, 7782-8.

[22] Gali-Muhtasib, H., Abou Kheir, W., Khei, L., Darwiche, N. \& Crooks, P., 2004b. Molecular pathway for Thymoqui-none-induced cell-cycle arrest and apoptosis in neoplastic keratinocytes. Anti-Cancer Drugs 15, 389-399.

[23] Roepke, M., Diestel, A., Bajbouj, K., Walluscheck, D., Schonfeld, P., Roessner, A., Schneider-Stock, R., Gali-Muhtasib, H., 2007. Lack of p53 augments Thymoquinone-induced apoptosis and caspase activation in human osteosarcoma cells. Cancer Biology and Therapy 6, 160-169. 
[24] Ragheb, A., Attia, A., Eldin, W.S., Elbarbry, F., Gazarin, S., Shoker, A., 2009. The protective effect of Thymoquinone, an anti-oxidant and anti-inflammatory agent, against renal injury. Saudi Journal of Kidney Diseases and Transplantation 20, 741-752.

[25] Okoh, V., Deoraj, A., Roy, D., 2011. Estrogen-induced reactive oxygen species-mediated signallings contribute to breast cancer. Biochimica et Biophysica Acta 1815, 115-133.

[26] Mansur, A.D.P., Silva, T.C.B.F., Takada, J.Y., Avakian, S.D., Strunz, C.M.C., Cesar, L.A.M., Aldrighi, J.M., Ramires, J.A.F., 2012. Long-Term Prospective Study of the Influence of Estrone Levels on Events in Postmenopausal Women with or at High Risk for Coronary Artery Disease. The Scientific World Journal 38, 149-156.

[27] Zhou, J., Seidel, E., 2010. Estrogens induce visfatin expression in 3T3-L1 cells. Peptides 31, 271-274.

[28] Arahamsson, A., Morad, V., Saarinen, N., Dabrosin, C., 2012. Estradiol, Tamoxifen, and Flaxseed Alter IL-1 $\beta$ and IL-1Ra Levels in Normal Human Breast Tissue in Vivo. Journal Clinical Endocrinology Metababolism 97, 2044-54.

[29] Marucci, C., Fishman, J., 1993. P450 enzymes of estrogen metabolism. Pharmacology and Therapeutic 57, 237-57.

[30] Mikstack, R., Rimando, A.M., Dutkiewicz, Z., Stefanski, T., Sobiak, S., 2012. Design, synthesis and evaluation of the inhibitory selectivity of novel transresveratrol analogues on human recombinant CYP1A1, CYP1A2 and CYP1B1. Bioorganic \& Medicinal Chemistry 20, 5117-26.

[31] Gao, H., Chakraborty, G., Lee-Lim, A.P., Mo, Q., Decker, M., Vonica, A., Shen, R., Brogi, E., Brivanlou, A.H., Giancotti, F.G., 2012. The BMP inhibitor coco reactivates breast cancer cells at lung metastatic sites. Cell 150, 764-779.

[32] Gajjar, K., Martin-Hirsch, P.L., Martin, F.L., 2012. CYP1B1 and hormone-induced cancer. Cancer Letters 324, 13-30.

[33] Mcfadyen, M.C.E., Murray, G.I., 2005. Cytochrome P450 1B1: a novel anticancer therapeutic target. Future Oncology 1, 259-263.

[34] Kawajiri, K., 1999. CYP1A1. IARC Science Publication 148, 159-172.

[35] Furukawa, M., Nishimura, M., Ogino, D., Chiba, R., Ikai, I., Ueda, N., Naito, S., Kuribayashi, S., Moustafa, M. A., Uchida, T., Sawada, H., Kamataki, T., Funae, Y., Fukumoto, M. 2004 Cytochrome p450 gene expression levels in peripheral blood mononuclear cells in comparison with the liver. Cancer Science 95, 520-529.

[36] Lin, Y., Yao, Y., Liu, S., Wang, L., Moorthy, B., Xiong, D., Cheng, T., Ding, X., Gu, J., 2012. Role of mammary epithelial and stromal P450 enzymes in the clearance and metabolic activation of 7,12-dimethylbenz(a)anthracene in mice. Toxicology Letters 212, 97-105.

[37] Williams-Brown, M.Y., Salih, S.M., Xu, X., Veenstra, T.D., Saeed, M., Theiler, S.K., Diaz-Arrastia, C.R., Salma, S.A., 2012. The effect of Tamoxifen and raloxifene on estrogen metabolism and endometrial cancer risk. Journal of Steroid Biochemical Molecular Biology 126, 78-86.

[38] Ashley-Martin, J., Vanleeuwen, J., Cribb, A., Andreou, P., Guernsey, J. R., 2012. Breast Cancer Risk, Fungicide Exposure and CYP1A1*2A Gene-Environment Interactions in a
Province-Wide Case Control Study in Prince Edward Island, Canada. International Journal of Environmental Research and Public Health 9, 1846-1858.

[39] Fu, J., Weise, A., Falany, J., Falany, C., Thibodeau, B., Miller, F., Kocarek, T., Runge-Morris, M. 2010. Expression of es-trogenicity genes in a lineage cell culture model of human breast cancer progression. Breast Cancer Research Treatment $120,35-45$

[40] Zhao, Y.N., Zhang, W., Chen, Y.C., Fang, F., Xiao-Quan, L., 2012. Relative imbalances in the expression of catechol-O-methyltransferase and cytochrome P450 in breast cancer tissue and their association with breast carcinoma. Maturitas 72, 139-145.

[41] Guengerich, P.F., Chun, Y., Kim, D., Gillam, E., Shimada, T., 2003. Cytochrome P450 1B1: a target for inhibition in anti-carcinogenesis strategies. Mutation Research/Fundamental and Molecular Mechanisms of Mutagenesis 523-524, 173-182.

[42] Scornaienchi, M.L., Thornton, C., Willett, K.L., \& Wilson, J.Y., 2010. Cytochrome P450-mediated 17b-estradiol metabolism in zebrafish (Danio rerio). Journal of Endocrinology 206, $317-325$.

[43] Han, E.H., Kim, H.G., Hwang, Y.P., Song, G.Y., Jeong, H.G., 2010. Prostaglandin E2 Induces CYP1B1 Expression via Ligand-Independent Activation of the ERa Pathway in Human Breast Cancer Cells. Toxicological Sciences 114, 204-216.

[44] Zahid, M., Kohli, E., Saeed, M., Rogan, E., Cavalieri, E., 2006. The Greater Reactivity of Estradiol-3,4-quinone vs Estradiol-2,3-quinone with DNA in the Formation of Depuri-nating Adducts: Implications for Tumour-Initiating Activity. Chemistry Research Toxicology 19, 164-172.

[45] Kemp, D.C., Fan, P.W., Stevens, J.C., 2002. Characterization of Raloxifen Glucuronidation in Vitro: Contribution of Intestinal Metabolism to Presystemic Clearance. Drug Metabolism and Disposition 30, 694-700.

[46] Lakhani, N.J., Sarkar, M.A., Venitz, J., Figg, W.D., 2003. 2-Methoxyestradiol, a Promising Anticancer Agent. Pharmacotherapy: The Journal of Human Pharmacology and Drug Therapy 23, 165-172.

[47] Ogura, K., Ishikawa, Y., Kaku, T., Nishiyama, T., Ohnuma, T., Muro, K., Hiratsuka, A., 2006. Quaternary ammonium-linked glucuronidation of trans-4-hydroxyTamoxifen, an active metabolite of Tamoxifen, by human liver microsomes and UDP-glucuronosyltransferase $1 \mathrm{~A} 4$ Biochemical Pharmacology 71, 1358-1369

[48] Berno, V., Amazit, L., Hinojos, C., Zhong, J., Mancini, M.G., Sharp, Z.D., Mancini, M.A., 2008. Activation of Estrogen Receptor- $\alpha$ by E2 or EGF Induces Temporally Distinct Patterns of Large-Scale Chromatin Modification and mRNA Transcrip-tion. PlosOne 3, e2286.

[49] Broker, L.E., Kruyt, F.A.E., Giaccone, G., 2005. Cell Death Independent of Caspases: A Review. Clinical Cancer Research $113155-3162$.

[50] Rajput, S., Kumar, B.N.P., Sarkar, S., Das, S., Azab, B., Santhekadur, P.K., Das, S.K., Emdad, L., Sarkar, D., Fisher, P.B., Mandal, M., 2013. Targeted Apoptotic Effects of Thymoquinone and Tamoxifen on XIAP Mediated Akt Regulation in Breast Cancer. PlosOne 8, e61342. 
[51] Jaiswal, A., Mcbride, O., Adesnik, M., Nebert, D., 1988. Human dioxin-inducible cytosolic NAD $(\mathrm{P}) \mathrm{H}: m e n a d i o n e$ oxi-doreductase. cDNA sequence and localization of gene to chromosome 16. Journal Biology Chemestry 263, $13572-13578$

[52] Liao, K., Niu, F., Hao, H.P., Wang, G.J., 2012. Advances on structure-activity relationship of NQO1-targeting antitumour quinones. Chinese Journal of Natural Medicines 10, 0170-0176.
[53] Yuan, W., Xu, L., Chen, W., Wang, L., Fu, Z., Pang, D., Li, D., 2011. Evidence on the association between NQO1 Pro187Ser polymorphism and breast cancer risk in the current studies: a meta-analysis. Breast Cancer Research and Treatment 125, 467-472.

[54] Dawling, S., Roodi, N., Parl, F.F., 2003. Methoxyestrogens Exert Feedback Inhibition on Cytochrome P450 1A1 and 1B1. Cancer Research 63, 3127-3132. 